\title{
Shock Capacitor Device
}

National Cancer Institute

\section{Source}

National Cancer Institute. Shock Capacitor Device. NCI Thesaurus. Code C76120.

The component of a defibrillator designed to store the electrical charge before it is delivered to the patient. 